\title{
Biomechanical Energy Harvesters Based on Ionic Conductive Organohydrogels via the Hofmeister Effect and Electrostatic Interaction
}

Yinghong Wu,${ }^{\dagger}$ Jingkui Qu,${ }^{\ddagger}$ Xinghan Zhang, ${ }^{\ddagger}$ Kelong Ao, ${ }^{\S}$ Zhiwen Zhou,${ }^{\dagger}$ Zeyang Zheng,${ }^{\dagger}$ Yijie Mu,${ }^{\dagger}$ Xinya $W u,{ }^{\dagger}$ Yang Luo ${ }^{*, \|}$ and Shien-Ping Feng, ${ }^{*, \dagger}$

†Department of Mechanical Engineering, The University of Hong Kong, Pokfulam Road, Hong Kong.

National Engineering Laboratory for Hydrometallurgical Cleaner Production Technology, Institute of Process Engineering, Chinese Academy of Sciences, Beijing 100190, China.

\$School of Energy and Environment, City University of Hong Kong, Kowloon, Hong Kong.

"Department of Physics, City University of Hong Kong, Kowloon, Hong Kong.

*Corresponding Authors: yluo24-c@my.cityu.edu.hk and hpfeng@hku.hk 


\section{Physical properties}

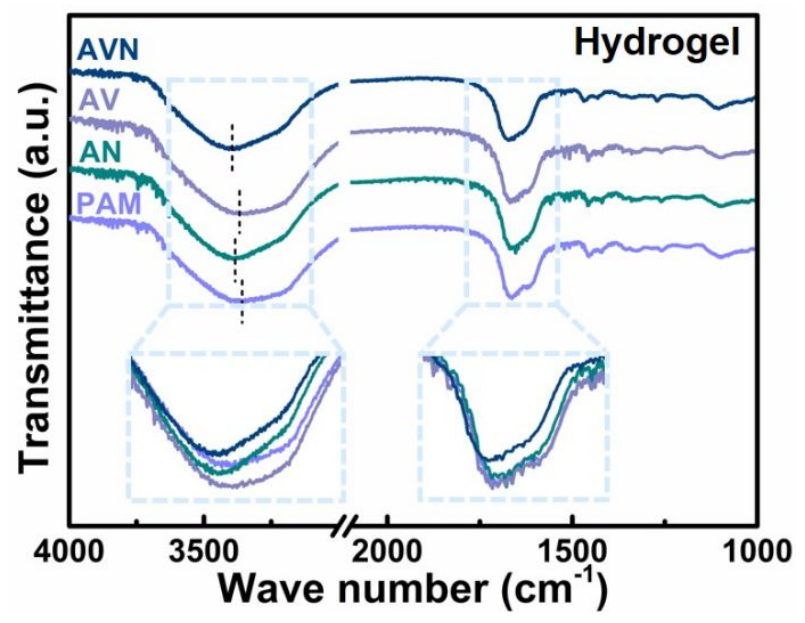

Figure S1. FTIR results of hydrogels. AN, AV and AVN represent $\mathrm{PAM} / \mathrm{NaCl}, \mathrm{PAM} / \mathrm{PVA}$ and $\mathrm{PAM} / \mathrm{PVA} / \mathrm{NaCl}$ hydrogels, respectively. The two peaks are associated with the hydroxy (left) and carbonyl (right) on the polymer network. The left shift and the reduced peak intensity with the addition of $\mathrm{NaCl}$ indicate the formation of hydrogel bonds and sodium bonds, respectively.

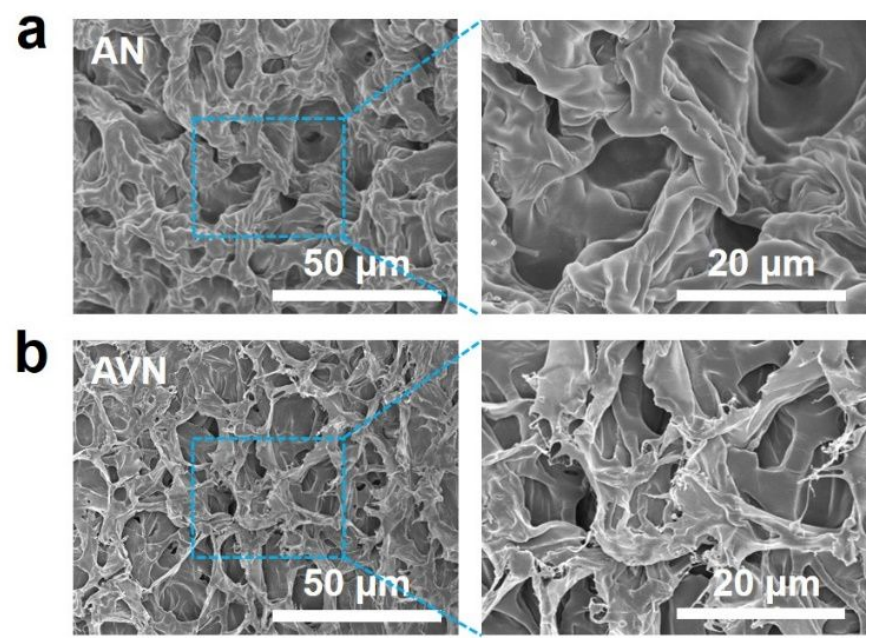

Figure S2. SEM images of AN and AVN hydrogels.

To further prove that double networks and sodium bonds contribute to the smaller conductivity decrease of AVN system after glycerol immersion, the Raman spectra of AV (PAM/PVA), AN (PAM/NaCl) and AVN (PAM/PVA/NaCl) systems before and after glycerol immersion (1-hour) are shown in Figure S3. Compared to those hydrogels, the increased CH stretching vibrations at $2896-2936 \mathrm{~cm}^{-1}$ of their corresponding organohydrogels indicate that a 
part of water has been successfully replaced by glycerol during the solvent replacement process. ${ }^{\mathrm{S} 1}$ Besides, compared to AV hydrogel with $\mathrm{OH}$ stretching bands of water at $3212-3387$ $\mathrm{cm}^{-1}$, both AN and AVN hydrogels show a much stronger peak at $3420-3437 \mathrm{~cm}^{-1}$, which belongs to the $\mathrm{OH}$ stretching bands of $\mathrm{NaCl}$ solution. ${ }^{\mathrm{S} 2}$ It is noted that the peak intensity $(\mathrm{OH}$ stretching bands of $\mathrm{NaCl}$ solution) of $\mathrm{AN}$ hydrogel is a little stronger than that of AVN hydrogel because the small content of PVA ( $10 \mathrm{wt} \%$ related to PAM) in AVN system leads to the slightly smaller ratio of $\mathrm{NaCl}$ (The theoretical content of $\mathrm{NaCl}$ is $9.261 \mathrm{wt} \%$ and $9.157 \mathrm{wt} \%$ in $\mathrm{AN}$ and AVN precursors, respectively.). After glycerol immersion, the peak intensity (OH stretching bands of $\mathrm{NaCl}$ solution) decreased in both $\mathrm{AN}$ and $\mathrm{AVN}$ systems, due to the excessive overflow of $\mathrm{NaCl}$ during the immersion process. However, it is worth noting that the peak intensity $(\mathrm{OH}$ stretching bands of $\mathrm{NaCl}$ solution) of $\mathrm{AVN}$ organohydrogel is inversely stronger than that of $\mathrm{AN}$ organohydrogel, indicating more amounts of $\mathrm{NaCl}$ remaining in the $\mathrm{AVN}$ system after solvent replacement.

On the other hand, the $\mathrm{Na}$ contents in remaining glycerol solutions after 1-hour immersion by $\mathrm{AV}, \mathrm{AN}$ and AVN hydrogels are measured by ICP-OES, as shown in Table S1. It is reasonable that there are no $\mathrm{Na}$ ions in the remaining glycerol solution after $\mathrm{AV}$ hydrogel immersion. However, the content of $\mathrm{Na}$ element of the remaining glycerol solution after AN hydrogel immersion is obviously higher than that after AVN hydrogel immersion. This means more $\mathrm{NaCl}$ remains in the glycerol solution after $\mathrm{AN}$ hydrogel immersion, indicating that the AVN system shows a smaller conductivity decrease after the solvent replacement process, compared with the AN system. 


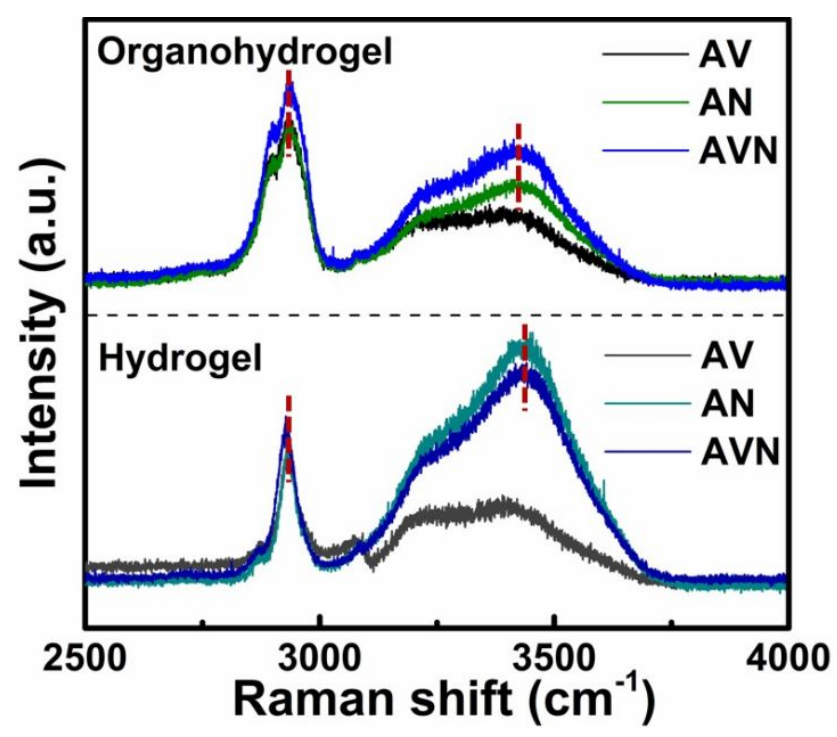

Figure S3. Raman spectra of various hydrogels and organohydrogels.

Table S1. ICP-OES results of Na content in the remaining glycerol solution after 1-hour immersion

\begin{tabular}{|c|c|c|}
\hline No. & Remaining glycerol solution $^{[1]}$ after different treatments & Na content \\
\hline 1 & After 1-hour immersion by AV hydrogel ${ }^{[2]}$ & $0 \mathrm{mg} / \mathrm{kg}$ \\
\hline 2 & After 1-hour immersion by AN hydrogel $[2]$ & $427.11 \mathrm{mg} / \mathrm{kg}$ \\
\hline 3 & After 1-hour immersion by AVN hydrogel ${ }^{[2]}$ & $158.10 \mathrm{mg} / \mathrm{kg}$ \\
\hline
\end{tabular}

Note: ${ }^{[1]}$ The remaining glycerol solution has been pre-treated as inorganic solution and diluted before ICPOES measurement. ${ }^{[2]}$ The weight and size of the immersed hydrogels are the same.

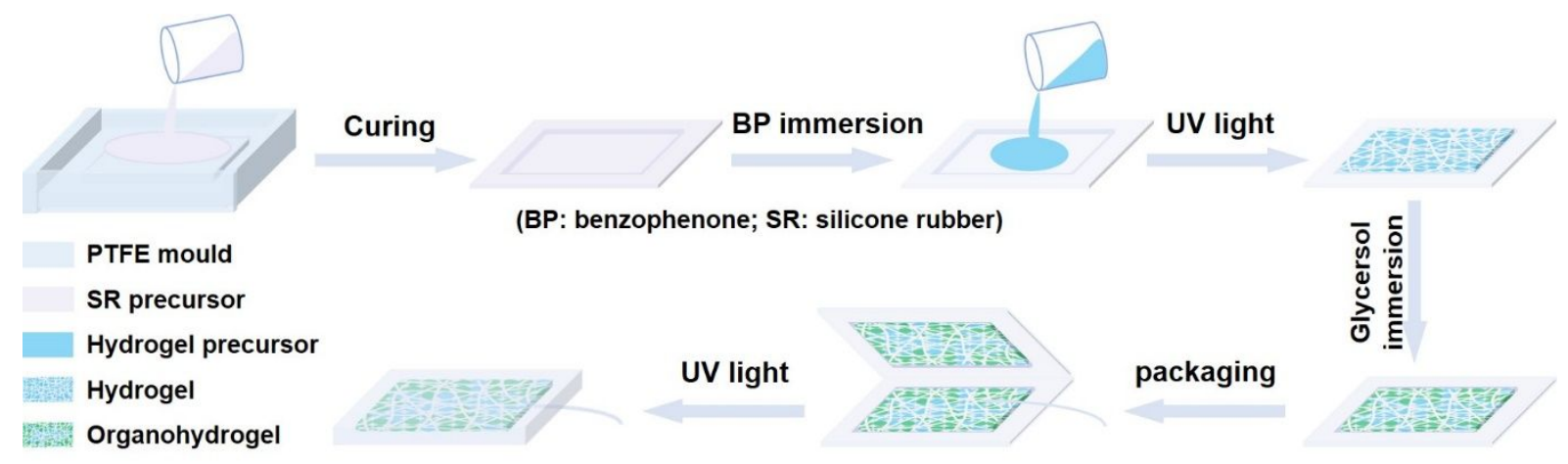

Figure S4. Device fabrication process. Schematic diagram of the fabrication process of AVN-based organohydrogel single-electrode TENG (AVN-based OHS-TENG). 

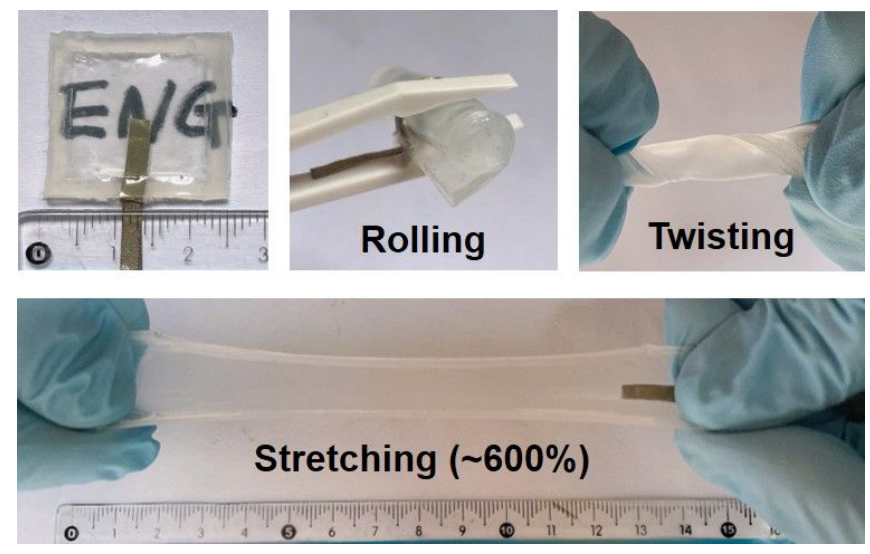

Figure S5. Flexibility and durability of the AVN-based OHS-TENG. Photographs of a typical AVNbased device (with 1-hour glycerol immersion) with rolling, twisting and stretching.

The strain-stress curve in Figure S6a shows that the tensile strength and elongation at break of AVN-based OHS-TENG were $222.7 \mathrm{KPa}$ and $761.3 \%$, respectively. It is noted that, compared to the AVN organohydrogel, the higher stress and lower strain of the AVN-based device is mainly attributed to the packaging silicone rubber (SR) film. The covered SR film helps to withstand part of tensile force since its stress is $5 \sim 6$ times of AVN organohydrogel as shown in Figure S6b. However, the strain of the AVN device will be limited by the SR film. As seen in the set of Figure S6a, the break occurs at the junction between the organohydrogel and SR, where the SR film at this point is much thinner and weaker.
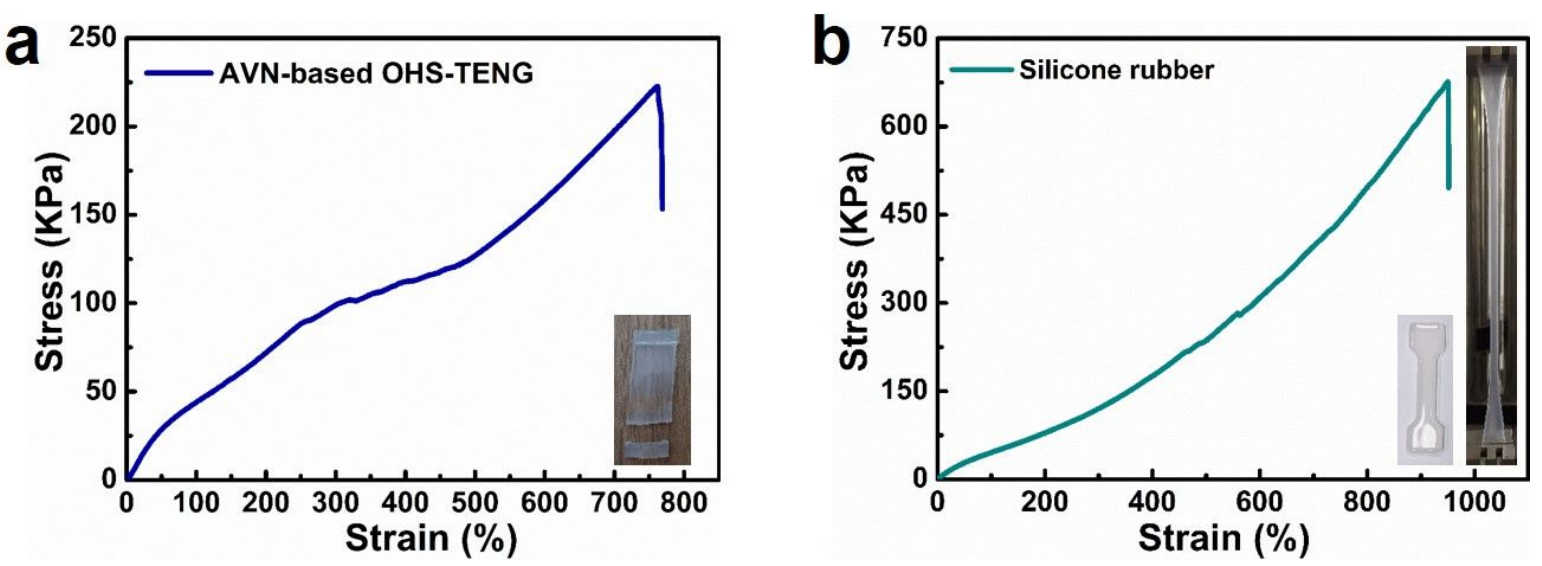

Figure S6. Mechanical properties of a) AVN-based OHS-TENG and b) silicone rubber (SR). The samples for the stress-strain test were prepared in a standard dumbbell-shape PTFE mold. 


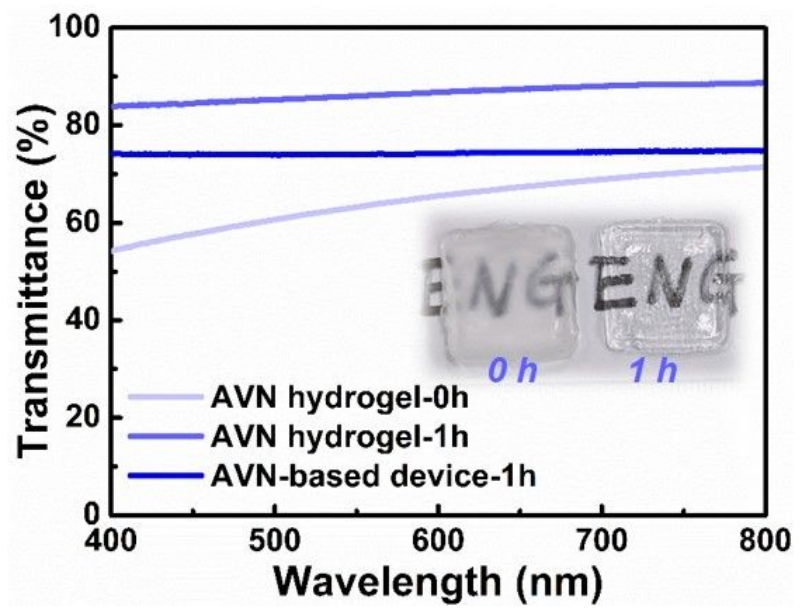

Figure S7. Optical transparency of the hydrogels. Transmittance spectra of AVN hydrogels ( $\sim 1 \mathrm{~mm}$ thick) and device ( $\sim 2 \mathrm{~mm}$ thick), inset is a comparison photograph of AVN hydrogels with or without 1-hour glycerol immersion.

\section{Anti-freezing and anti-drying properties}

The replacement of water with glycerol can solve the problems of easy-to-dry, short lifetime and narrow operating temperature window in the common hydrogels, leading to the formation of anti-drying and anti-freezing organohydrogel. To verify its anti-drying property, the weight retention rates of AVN-based organohydrogels and their corresponding TENGs based on various glycerol immersion times are plotted in Figure S8. It is found that the weight retention of these samples and devices are mainly dependent on the glycerol immersion time. Without glycerol soaking, the weight of the hydrogel and device dropped quickly and dried out in one week and two weeks, respectively. With glycerol immersion, the hydrogel and the device can maintain their weight at $73 \sim 104 \%$ and $95 \sim 102 \%$, respectively, even after three months of storage under ambient condition $\left(25^{\circ} \mathrm{C}, 30 \% \mathrm{RH}\right)$; it proved the non-volatile property of the glycerol solvent and the effectiveness of the SR film to protect the device. It is noting that the hygroscopic nature of glycerol will cause a slight increase in weight more than $100 \%$, because water molecules are captured by the organohydrogels from environmental moisture. ${ }^{16}$ Intriguingly, as the storage time increases, the weight of the AVN-based OHS-TENG fluctuates up and down at a certain point to maintain the water-oil balance in the hydrogel, so that the 
device never seems to dry out. In the reported hydrogels ${ }^{12-15,28,31-33}$ and HS-TENGs ${ }^{12-15,28,31-32}$ under similar storage conditions, the longest storage time is only one month (with the weight retention of 50 90\% for hydrogels and $93 \sim 95 \%$ for devices) as summarized in Figure S8.

The anti-freezing test was conducted by storing the AVN-based devices with or without glycerol immersion in the freezer at $-20{ }^{\circ} \mathrm{C}$. As seen in Figure S9a, the hydrogel electrode inside AVN devices without glycerol immersion quickly turned white after one day of storage while the one with 1-hour glycerol immersion maintained its originality and flexibility after four-month storage. To further test the anti-drying and anti-freezing properties, the AVN-based hydrogels with various glycerol soaking time $(0-5 \mathrm{~h})$ were stored in the vacuum freeze-drier $(-$ $\left.50{ }^{\circ} \mathrm{C}\right)$. Figure S8b shows that the sample without glycerol immersion dried in $4 \mathrm{~h}$ and those with $0.5-5 \mathrm{~h}$ glycerol immersion still maintained their transparency and flexibility after $96 \mathrm{~h}$.
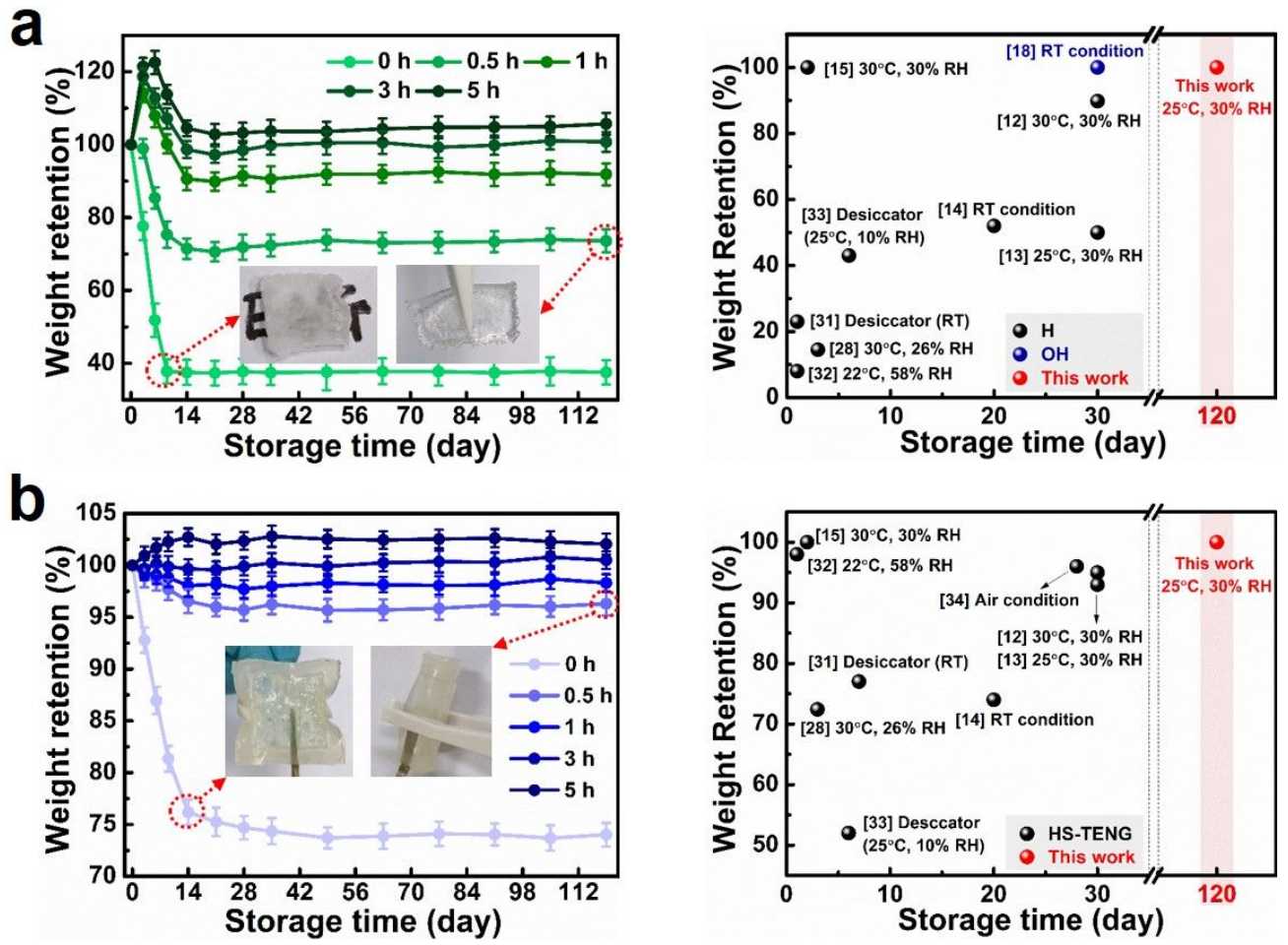

Figure S8. Anti-drying property of a) hydrogels and b) devices. Weight retention with different glycerol immersion time over four-month storage in lab air condition and comparison with reported works. 
a

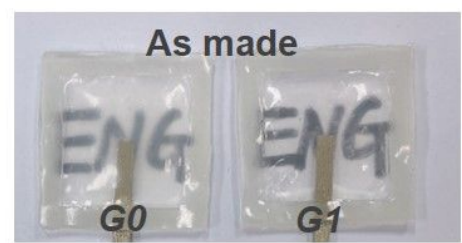

$-20{ }^{\circ} \mathrm{C}$

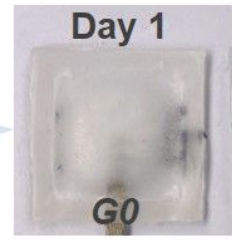

b
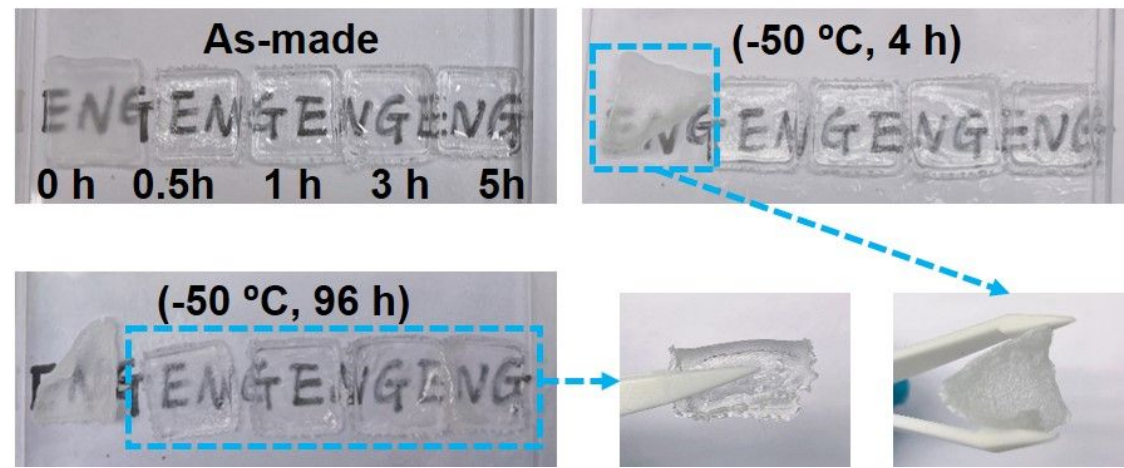

Figure S9. Anti-freezing properties of the hydrogels and devices: a) Photograhps of AVN OHS-TENG with or without 1-hour glycerol immersion for storing in a $-20{ }^{\circ} \mathrm{C}$ freezer for four months, b) photographs of AVN hydrogels with different glycerol immersion time after storing in a $-55^{\circ} \mathrm{C}$ freeze-drier. Note that the measured temperature inside the freeze-drier is around $-50{ }^{\circ} \mathrm{C}$.

\section{Conductivity and output performance}

a

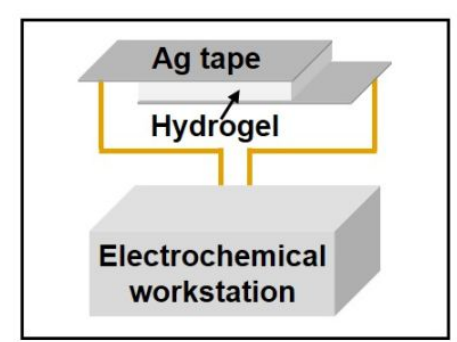

C

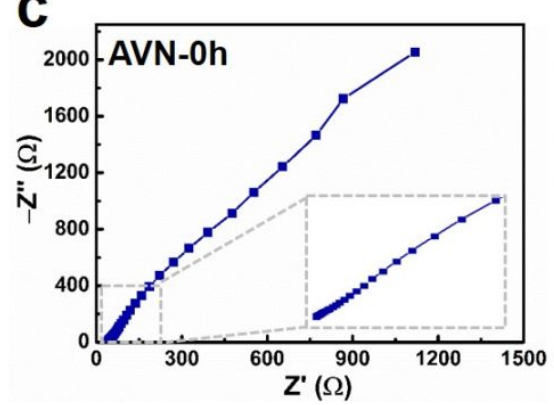

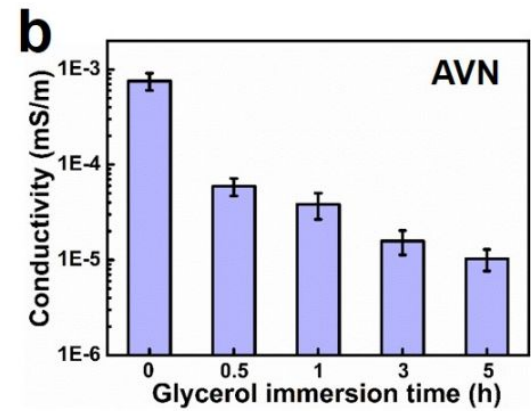

d

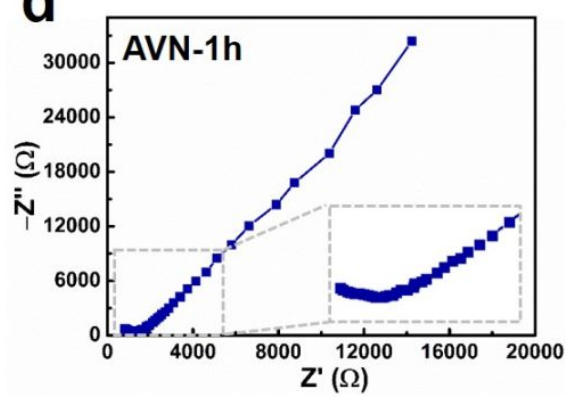

Figure S10. Conductivity of the hydrogels. a) Schematic diagram of conductivity measurement system, where the samples were sandwiched by two Ag tapes connecting to the electrochemical workstation, b) conductivity of AVN hydrogels with different glycerol immersion time, the Nyquist plots of AVN hydrogel c) without or d) with 1-hour glycerol immersion. 

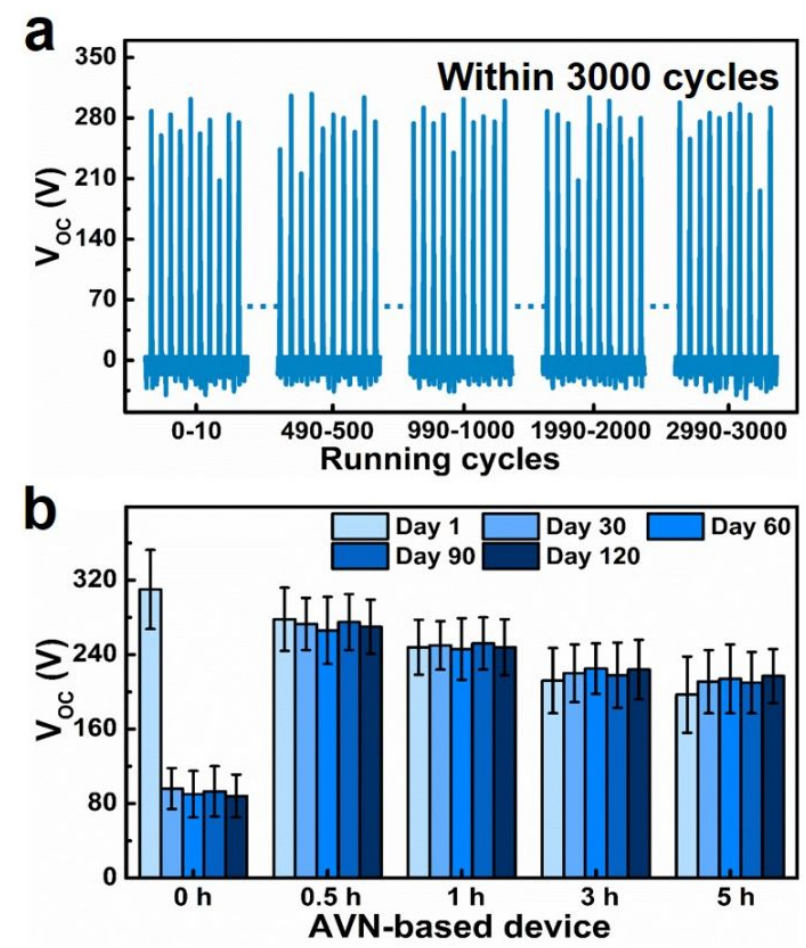

Figure S11. Long-term output stability of AVN-based OHS-TENG. a) Within 3000 cycles, and b) after four-month storage at ambient condition $\left(25^{\circ} \mathrm{C}, 30 \% \mathrm{RH}\right)$.

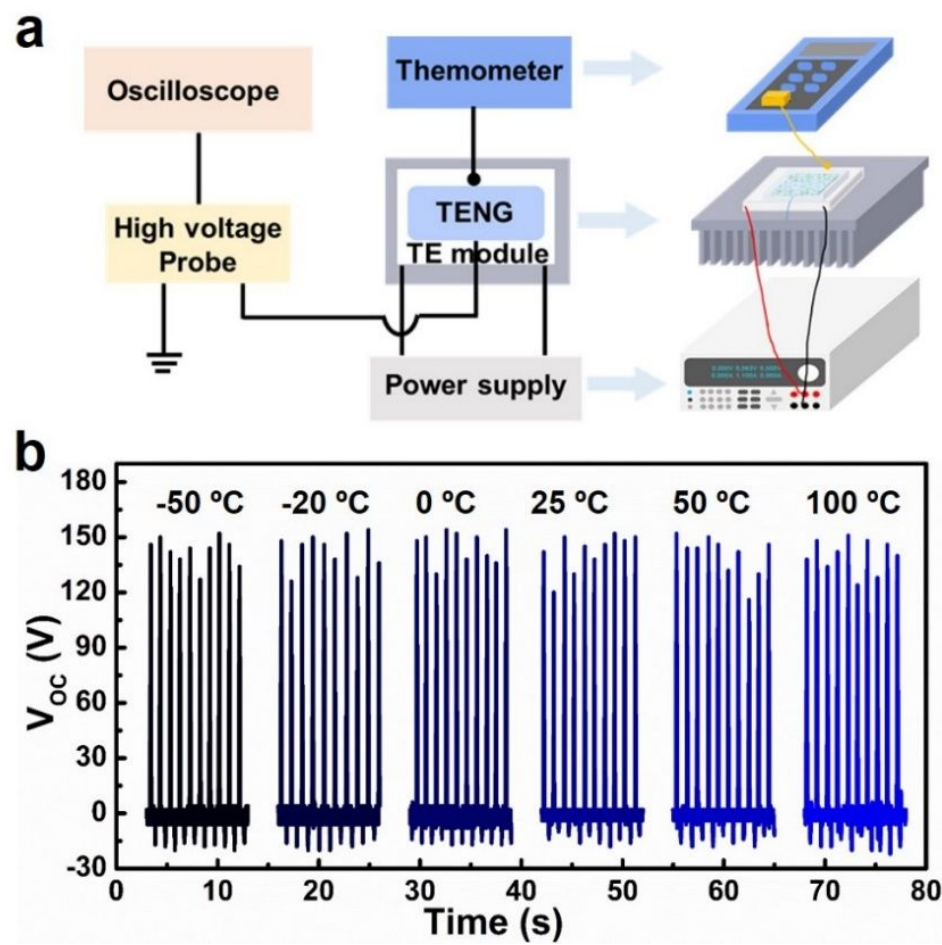

Figure S12. Real-time temperature-output monitoring to study the temperature effect on the output. a) Schematic diagram of the temperature control system, and b) $V_{O C}$ of AVN-based OHS-TENG at different temperature. The device can maintain almost the same output over a wide temperature range of $-50 \sim 100^{\circ} \mathrm{C}$. Note that the measurement for $-50{ }^{\circ} \mathrm{C}$ was conducted in a freeze-drier. 
Figure S13a presents the normalized $\mathrm{V}_{\mathrm{OC}}$ of AVN OHS-TENG under different relative humidity $(\mathrm{RH})$ to investigate the potential effect of environmental humidity on the device output. It is observed that the normalized $\mathrm{V}_{\mathrm{OC}}$ values are close to 1.0 and no obvious trend is found over a wide $\mathrm{RH}$ range from $29 \%$ to $81 \%$, indicating the output stability of AVN OHSTENG under various RH conditions. This is mainly due to the device structure design in this study, where the organohydrogel is fully covered and encapsulated by the water-proof silicone rubber as shown in Figure S4. On the other hand, the sweat on the skin may affect the device output, and thus, $\mathrm{V}_{\mathrm{OC}}$ signals obtained by dry or sweaty hand tapping are compared in this study. As shown in Figure S13b, although the output stability of the device induced by sweaty hand is lower than that by dry hand, there is no obvious output difference among these two states. Similar to human skin, water and $\mathrm{NaCl}$ solution with low concentration are often considered as positive triboelectric materials for blue energy harvesting. ${ }^{\mathrm{S} 3-\mathrm{S} 7}$ Therefore, the sweat on the skin tends to be positively charged when contacted with the device. The small amount of sweat left on the device may be the main factor cause the output instability, but it will evaporate soon in the ambient environment and thus won't significantly affect the device output.
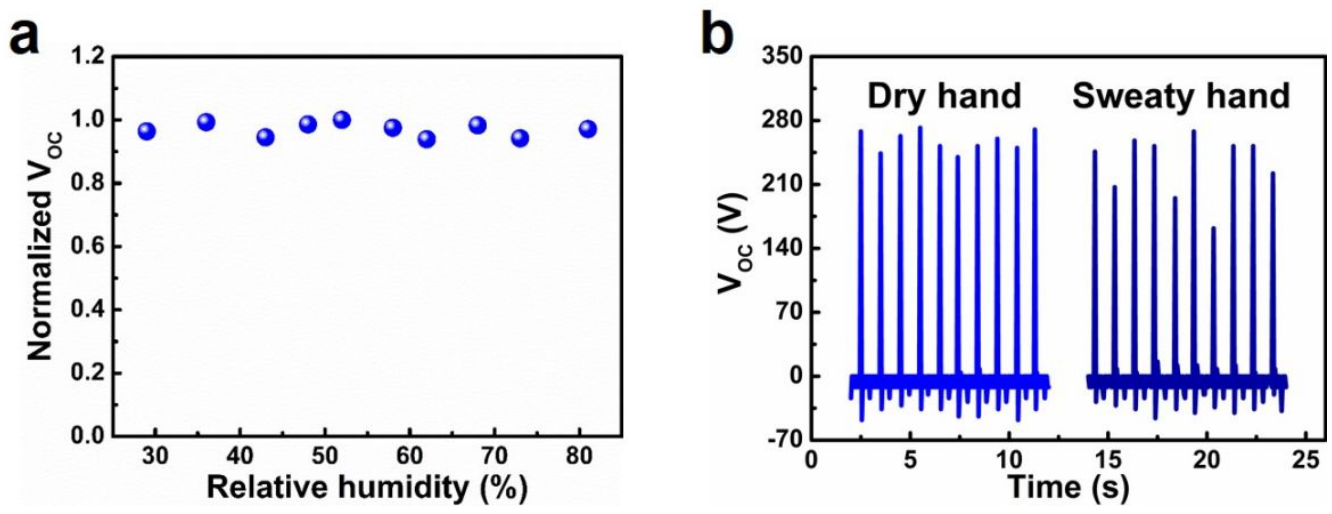

Figure S13. Effect of a) environmental humidity and b) human sweat on the device output. 

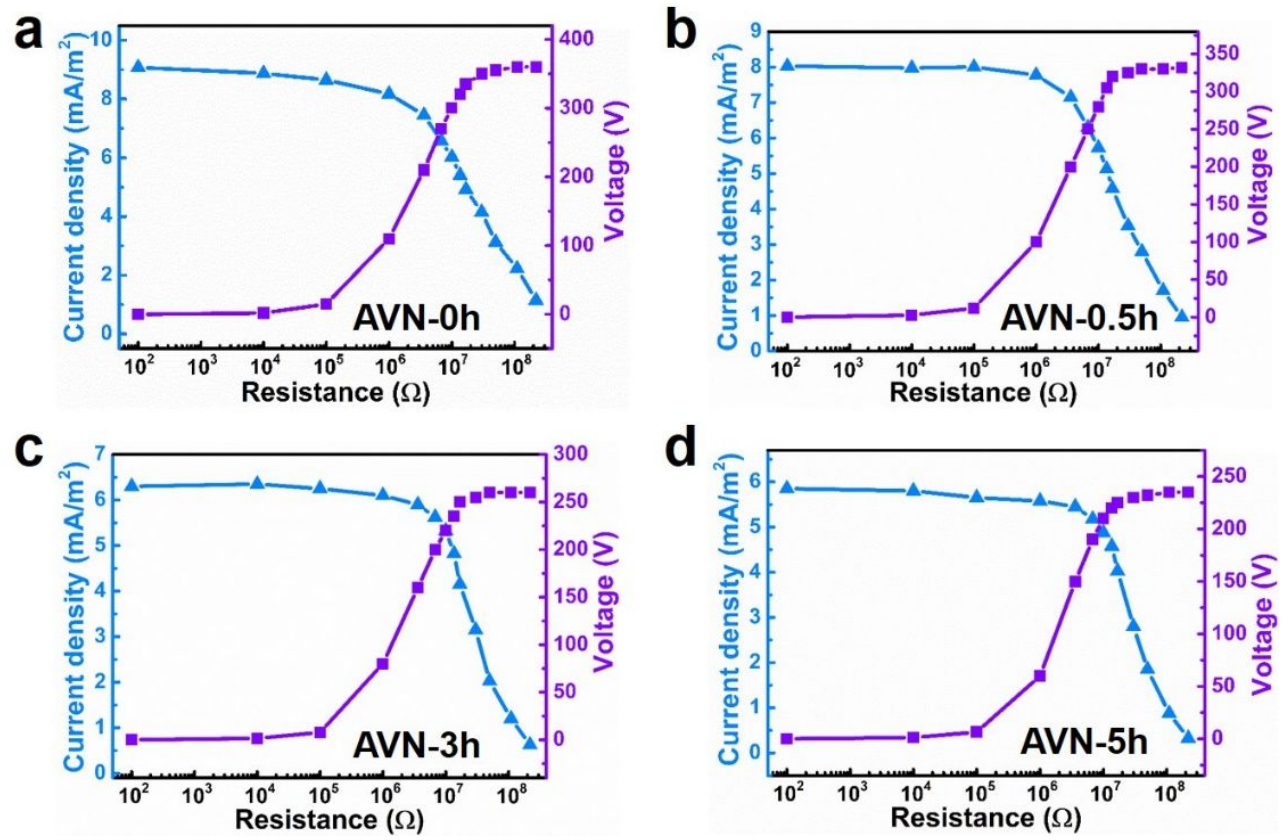

Figure S14. Resistance behavior of AVN-based device with different glycerol immersion time. a) 0 hour, b) 0.5 hours, c) 3 hours, and d) 5 hours.
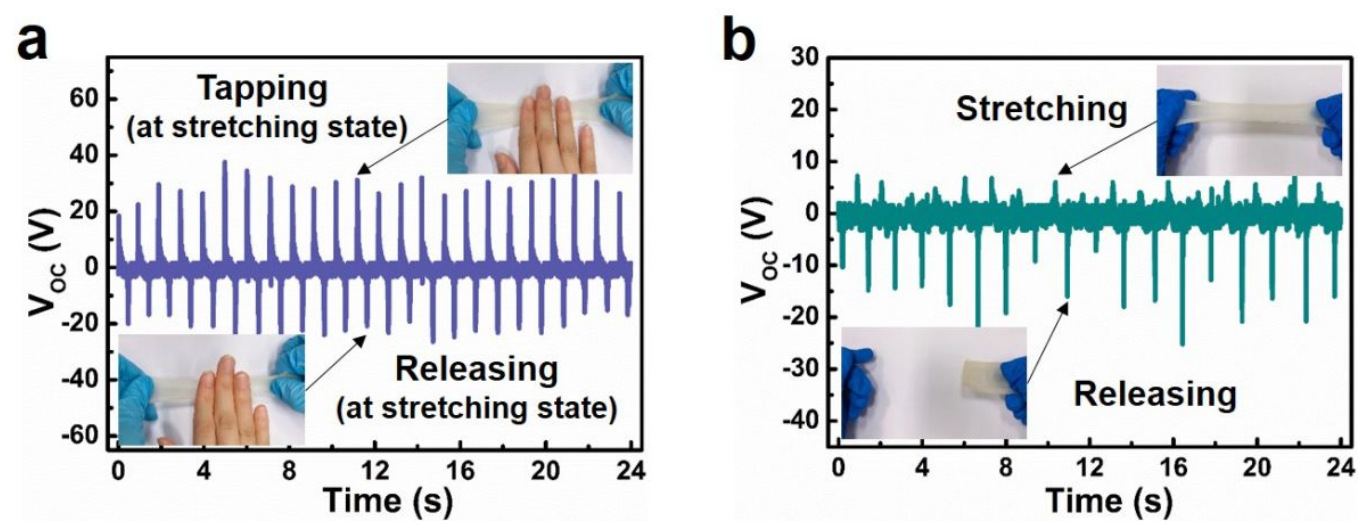

Figure S15. $V_{O C}$ response to body motions such as a) continuous stretching \& releasing and b) tapping a stretching device. 


\section{Comparison}

Table S2. Comparison with typical HS-TENGs ${ }^{12-15,28,31,37-40}$ and OHS-TENGs ${ }^{17,18}$ reported recently.

\begin{tabular}{|c|c|c|c|c|c|c|c|c|c|c|}
\hline \multirow[b]{2}{*}{ Ref. } & \multicolumn{3}{|c|}{ Material and size } & \multicolumn{3}{|c|}{ Physical properties } & \multicolumn{3}{|c|}{ Output performance } & \multirow{2}{*}{$\begin{array}{l}\text { Output } \\
\text { stability }\end{array}$} \\
\hline & Hydrogel & Tribo-layer & $\begin{array}{c}\text { E-Size } \\
\left(\mathrm{cm}^{2}\right)\end{array}$ & $\begin{array}{c}\text { Anti- } \\
\text { freezing }\end{array}$ & $\begin{array}{c}\text { Anti- } \\
\text { drying }\end{array}$ & $\begin{array}{c}\text { Strain } \\
(\%)\end{array}$ & $\begin{array}{l}\mathbf{V}_{\text {OC }} \\
\text { (V) }\end{array}$ & $\underset{\left(\mathbf{m A} / \mathbf{m}^{2}\right)}{\mathbf{J}_{\mathrm{SC}}}$ & $\begin{array}{l}\text { Power } \\
\text { density }\end{array}$ & \\
\hline$[40]$ & PAM-gelation & PU-SR & $6 \times 6$ & No & No & 300 & 383.8 & \begin{tabular}{|c|}
7.47 \\
$(26.9 \mu \mathrm{A})$ \\
\end{tabular} & $\begin{array}{c}1.25 \\
\mathrm{~W} / \mathrm{m}^{2} \\
\end{array}$ & I \\
\hline [39] & Starch-PDMS & SR & $0.4 \times 25$ & No & No & 200 & 25 & \begin{tabular}{c|}
$\sim 2$ \\
$(\sim 2 \mu \mathrm{A})$ \\
\end{tabular} & I & I \\
\hline$[38]$ & PVA & PDMS & $8 \times 8$ & No & No & 35 & 200 & \begin{tabular}{c|}
3.52 \\
$(22.5 \mu \mathrm{A})$ \\
\end{tabular} & $\begin{array}{c}0.3 \mathrm{~W} / \mathrm{m}^{2} \\
(2 \mathrm{~mW})\end{array}$ & I \\
\hline [37] & PVA-borax & PDMS & $4 \times 4$ & No & No & 900 & $\sim 64$ & \begin{tabular}{|c|}
$\sim 0.31$ \\
$(\sim 0.5 \mu \mathrm{A})$ \\
\end{tabular} & $\begin{array}{c}5 \\
\mathrm{~mW} / \mathrm{m}^{2} \\
\end{array}$ & $\begin{array}{c}14 \text { days } \\
\left(100 \% \mathrm{~V}_{\mathrm{OC}}\right)\end{array}$ \\
\hline$[31]$ & PAM-LiCl & PDMS & $4 \times 4$ & No & No & 330 & 277 & \begin{tabular}{c|}
13.75 \\
$(\sim 22 \mu \mathrm{A})$ \\
\end{tabular} & $\begin{array}{c}4.22 \\
\mathrm{~W} / \mathrm{m}^{2} \\
\end{array}$ & $\begin{array}{c}7 \text { days } \\
\left(83.5 \% \mathrm{~V}_{\mathrm{OC}}\right)\end{array}$ \\
\hline$[28]$ & PAM-alginate & PDMS & $2 \times 1$ & No & No & 397 & 70 & $\begin{array}{c}2.3 \\
(0.46 \mu \mathrm{A}) \\
\end{array}$ & $\begin{array}{c}135 \\
\mathrm{~mW} / \mathrm{m}^{2} \\
\end{array}$ & $\begin{array}{c}21 \text { days } \\
\left(98 \% \mathrm{~V}_{\mathrm{OC}}\right)\end{array}$ \\
\hline [15] & PAA-PDMAPS & PDMS & $2.5 \times 2.5$ & $-20^{\circ} \mathrm{C}$ & $100^{\circ} \mathrm{C}$ & 400 & 117 & \begin{tabular}{|c|}
22.88 \\
$(14.3 \mu \mathrm{A})$ \\
\end{tabular} & $\begin{array}{c}1.3 \\
\mathrm{~W} / \mathrm{m}^{2} \\
\end{array}$ & $\begin{array}{c}30 \text { days } \\
\left(100 \% \mathrm{~V}_{\mathrm{OC}}\right)\end{array}$ \\
\hline$[14]$ & PAM-HEC & SR & $3 \times 3$ & $-20{ }^{\circ} \mathrm{C}$ & $25.8^{\circ} \mathrm{C}$ & 150 & 285 & $\begin{array}{c}17.22 \\
(15.5 \mu \mathrm{A})\end{array}$ & $\begin{array}{c}626 \\
\mathrm{~mW} / \mathrm{m}^{2}\end{array}$ & $\begin{array}{c}20 \text { days } \\
\left(89.3 \% \mathrm{~V}_{\mathrm{OC}}\right)\end{array}$ \\
\hline [13] & Cellulose/PVA & VHB & $1 \times 1.5$ & $0^{\circ} \mathrm{C}$ & $60^{\circ} \mathrm{C}$ & 500 & 41 & \begin{tabular}{|c|}
3.33 \\
$(0.5 \mu \mathrm{A})$ \\
\end{tabular} & 1 & $\begin{array}{c}30 \text { days } \\
\left(100 \% \mathrm{~V}_{\mathrm{OC}}\right)\end{array}$ \\
\hline$[12]$ & PAM-LiCl & PDMS & $3 \times 4$ & $0{ }^{\circ} \mathrm{C}$ & $60^{\circ} \mathrm{C}$ & 1160 & 145 & \begin{tabular}{|c|}
1.25 \\
$(1.5 \mu \mathrm{A})$ \\
\end{tabular} & $\begin{array}{c}35 \\
\mathrm{~mW} / \mathrm{m}^{2} \\
\end{array}$ & $\begin{array}{c}30 \text { days } \\
\left(100 \% \mathrm{~V}_{\mathrm{OC}}\right)\end{array}$ \\
\hline [17] & PAM/Clay & IU-PDMS & $4 \times 4$ & $-30^{\circ} \mathrm{C}$ & $80{ }^{\circ} \mathrm{C}$ & I & 157 & $\begin{array}{c}10 \\
(16 \mu \mathrm{A})\end{array}$ & $\begin{array}{c}710 \\
\mathrm{~mW} / \mathrm{m}^{2}\end{array}$ & I \\
\hline [18] & $\mathrm{PAM} / \mathrm{MMT} / \mathrm{CNT}$ & $\begin{array}{l}\text { PU tape } \\
\& \text { SR }\end{array}$ & $3 \times 4$ & $-60^{\circ} \mathrm{C}$ & $60{ }^{\circ} \mathrm{C}$ & 500 & 86.4 & \begin{tabular}{|c|}
0.92 \\
$(1.1 \mu \mathrm{A})$ \\
\end{tabular} & $\begin{array}{c}41.2 \\
\mathrm{~mW} / \mathrm{m}^{2}\end{array}$ & $\begin{array}{c}60 \text { days } \\
\left(\sim 95 \% \mathrm{~V}_{\mathrm{OC}}\right) \\
\end{array}$ \\
\hline $\begin{array}{l}\text { This } \\
\text { work }\end{array}$ & PAM/PVA-NaCl & SR & $2 \times 2$ & $-55^{\circ} \mathrm{C}$ & $120^{\circ} \mathrm{C}$ & 600 & $\begin{array}{l}150- \\
350\end{array}$ & $\begin{array}{l}3.78- \\
8.95\end{array}$ & $\begin{array}{l}1.0-1.8 \\
\mathrm{~W} / \mathrm{m}^{2}\end{array}$ & $\begin{array}{c}120 \text { days } \\
\left(100 \% \mathrm{~V}_{\mathrm{OC}}\right)\end{array}$ \\
\hline
\end{tabular}

\section{Reference}

[S1] Mendelovici, E.; Frost, R. L.; Kloprogge, T. Cryogenic Raman Spectroscopy of Glycerol. J. Raman Spectrosc. 2000, 31, 1121-1126.

[S2] Sun, Q. Raman Spectroscopic Study of the Effects of Dissolved $\mathrm{NaCl}$ on Water Structure. Vib. Spectrosc. 2012, 62, 110-114.

[S3] You, J.; Shao, J.; He, Y.; Yun, F. F.; See, K. W.; Wang, Z. L.; Wang, X. High-Electrification Performance and Mechanism of a Water-Solid Mode Triboelectric Nanogenerator. ACS Nano 2021, 15, 8706-8714.

[S4] Xu, W.; Zheng, H.; Liu, Y.; Zhou, X.; Zhang, C.; Song, Y.; Deng, X.; Leung, M.; Yang, Z.; Xu, R. X.; Wang, Z. L.; Zeng, X. C.; Wang, Z. A. Droplet-Based Electricity Generator with High Instantaneous Power Density. Nature 2020, 578, 392-396.

[S5] Jiang, P.; Zhang, L.; Guo, H.; Chen, C.; Wu, C.; Zhang, S.; Wang, Z. L. Signal Output of Triboelectric Nanogenerator at Oil-Water-Solid Multiphase Interfaces and Its Application for Dual-Signal Chemical Sensing. Adv. Mater. 2019, 31, 1902793.

[S6] Yang, X.; Chan, S.; Wang, L.; Daoud, W. A. Water Tank Triboelectric Nanogenerator for Efficient Harvesting of Water Wave Energy over a Broad Frequency Range. Nano Energy 2018, 44, 388-398.

[S7] Lin, Z-H.; Cheng, G.; Wu, W.; Pradel, K. C.; Wang, Z. L. Dual-Mode Triboelectric Nanogenerator for Harvesting Water Energy and as a Self-Powered Ethanol Nanosensor. ACS Nano 2014, 8, 6440-6448. 